Research Article

\title{
Dietary Practice among Type 2 Diabetic Ppatients in Southern Ethiopia
}

\author{
Kidus Temesgen Worsa $\mathbb{D D}^{1}{ }^{1}$ Beakal Zinab, ${ }^{2}$ and Melese Sinaga Teshome ${ }^{2}$ \\ ${ }^{1}$ School of Public Health, College of Health Science, Arba Minch University, Arba Minch, Ethiopia \\ ${ }^{2}$ Department of Nutrition and Dietetics, Faculty of Public Health, Health Institute, Jimma University, Jimma, Ethiopia
}

Correspondence should be addressed to Kidus Temesgen Worsa; kidus.temesgen@amu.edu.et

Received 6 September 2021; Revised 5 December 2021; Accepted 13 December 2021; Published 27 December 2021

Academic Editor: Faustino R. Perez-Lopez

Copyright $@ 2021$ Kidus Temesgen Worsa et al. This is an open access article distributed under the Creative Commons Attribution License, which permits unrestricted use, distribution, and reproduction in any medium, provided the original work is properly cited.

\begin{abstract}
Background. Diabetic patients' dietary practice is critical to improve glycemic, lipid, and blood pressure control. However, a significant number of patients had poor dietary practice. In Ethiopia, more than half of diabetic patients were not practicing a healthy dietary approach. Therefore, this study assessed variables that were hardly addressed in previous studies. The aim of this study was to assess dietary practice and associated factors among patients with type 2 diabetes. Methods. A facilitybased cross-sectional study was performed among patients with type 2 diabetes in Arba Minch General Hospital from April 21 to May 20, 2020. A systematic sampling technique was used to select 352 patients. The data were entered into EpiData version 3.1 and exported to SPSS version 21 for cleaning and analysis. Descriptive statistics were performed. All variables in bivariate analysis with $p$-value $<0.25$ were entered into a multivariable logistic regression model, and statistical significance was declared at a $p$-value of less than 0.05 . Results. The prevalence of poor dietary practice was found to be $40.6 \%$ (95\%CI (35.7-46.0)). After adjusting for other variables in multivariable analysis, not attending formal education $(\mathrm{AOR}=3.0 ; 95 \% \mathrm{CI}$ $(1.6-5.5))$, being at primary education level $(\mathrm{AOR}=2.2 ; 95 \% \mathrm{CI}(1.1-4.4))$, being moderately food insecure $(\mathrm{AOR}=5.3 ; 95 \%$ $\mathrm{CI}(2.8-9.9))$, having depression $(\mathrm{AOR}=5.9 ; 95 \% \mathrm{CI}(3.0-11.4))$, and not having nutrition education $(\mathrm{AOR}=2.2 ; 95 \%$ (1.1-4.6)) were factors associated with poor dietary practice. Conclusions. A significant proportion of patients had poor dietary practice. The poor dietary practice was significantly higher among those with no formal education, at the primary education level, from the moderately food-insecure household, having depression, and not having nutrition education. The results imply the need for strengthening health information dissemination concerning healthy dietary practice in the form of a package.
\end{abstract}

\section{Introduction}

Type 2 diabetes accounts for $90-95 \%$ of those with diabetes, previously referred to as noninsulin-dependent diabetes or adult-onset diabetes and encompasses individuals who have insulin resistance and usually have relative (rather than absolute) insulin deficiency. It is a metabolic disorder manifested by increased blood glucose level and caused by a complex interaction of genetics and environmental factors. Diabetic patients usually experience acute, chronic, or both complications. Acute complications of poorly managed diabetes are hyperglycemia and hypoglycemia. The chronic complications are associated with long-standing impairment, malfunction, and failure of different organs, especially the eyes, kidneys, nerves, heart, and blood vessels [1-3].

Dietary shifts almost concurrently occur with demographic and epidemiologic shifts. Motorized ways of life and mechanization contribute to an increased prevalence of nutrition-related noncommunicable diseases. There are limited pieces of evidence on effective strategies to prevent the onset of poor nutritional status in low- and middleincome countries (LMICs) [4-6].

Globally, in 2019, half a billion people are estimated to be living with diabetes, representing $9.3 \%$ of the global adult population. This figure will increase to 578 million (10.2\%) in 
2030 and 700 million (10.9\%) in 2045 [7]. The percentage of premature deaths attributable to diabetes is higher in low- and middle-income countries than in high-income countries [8].

Nutrition is crucial in the prevention or delay and management of type 2 diabetes including those already on medications. The primary goals of nutrition therapy for diabetes are to improve glycemic, lipid, and blood pressure control, thus contributing to reduced risk for potential longterm complications of diabetes and heart disease, and to improve the quality of life of individuals with diabetes. A diet that is diverse in food groups is independently associated with a lower risk of type 2 diabetes. People who reported consuming a diversified diet had a $30 \%$ reduced incidence of type 2 diabetes. Low-calorie eating patterns, specifically higher intakes of nuts, berries, yogurt, coffee, and tea, are associated with reduced diabetes risk. On the other hand, red meats and sugar-sweetened beverages are associated with a high risk of type 2 diabetes [8-12].

Mortality and morbidity associated with noncommunicable disease (NCD) surprisingly increased in lowand middle-income countries. In 2016, $78 \%$ of all NCD deaths and $85 \%$ of premature adult NCD deaths happened in low- and middle-income countries (LMICs) [13-15]. This burden is more observed in the working age (15-64 years of age) of the regions [16]. In Africa, the prevalence of diabetes increased from $3.1 \%$ (4 million) in 1980 to $7.1 \%$ (25 million) in 2014 [17]. With this trend, Africa is out of track in realizing the NCD pointers from the set global and continental target [18]. In Ethiopia, NCD alone was responsible for $39 \%$ of all deaths, and out of which, diabetes attributed to $2 \%$ of all deaths. Tobacco use, poor diet, harmful use of alcohol, and obesity were dominant risk factors for the causation of NCD [15].

Diabetic patients' dietary practice is the key to the management of type 2 diabetes and the prevention of complications related to hyperglycemia [12, 19]. However, the patients' dietary practice was poor and underemphasized in the diabetes management component [20].

There were extensive works that had been performed by governments of low-income countries addressing the increasing prevalence of type 2 diabetes via various health strategies and policies. The second Ethiopian National Nutrition Program (NNP-II) has given a place for NCDs through numerous initiatives. However, the burden is still high $[21,22]$. In sub-Saharan Africa (SSA), diabetic patients hardly practice the advised diet and also $33 \%$ to $87 \%$ of patients had a poor level of knowledge about diabetes-related complications [23]. As a result, sugar-sweetened beverages (SSB) were highly consumed and pointedly contributed to total sugar and energy consumption in SSA [21].

In Ethiopia, diabetes is a major public health problem in the contemporary era. Concomitantly, more than half of diabetic patients were not practicing the perceived healthy dietary approach. Some of the identified factors were eating out of home, attending diabetic nutrition education, and having the disease for more than 10 years [24]. Additionally, facing difficulty to choose foods, nonavailability of fruits and vegetables, and worrying about the high cost of foods were the factors significantly associated with poor dietary practice [25].

It was agreed that dietary management had a central role in diabetic management, but little is known about the dietary practice and associated factors in Ethiopia, in general, and in the study area, in particular, and also very crucial variables were not addressed in the past studies regarding their dietary practice. Therefore, this study assessed variables that were hardly addressed in previous studies performed both in Ethiopia and particularly the study area, concerning dietary practice among patients with type 2 diabetes.

\section{Methods and Materials}

2.1. Study Area and Period. The study was conducted from April 21 to May 20, 2020, in Arba Minch General Hospital. Arba Minch is the capital town of Gamo Zone located $505 \mathrm{~km}$ far to the south of Addis Ababa, the capital city of Ethiopia and $272 \mathrm{~km}$ from Hawassa, center of Southern Nations, Nationalities, and People's Regional State (SNNPR). The town is one of the low-land areas in the SNNPR having a hot climate with an average temperature of $29^{\circ} \mathrm{C}$ and annual mean rainfall of $900 \mathrm{~mm}$. An estimated population of 128,721 was living in Arba Minch town. There was one general hospital, one primary hospital, and two health centers currently proving health service [26]. The area is well known for its fruit production such as banana, mango, apple, avocado, orange, papaya, and vegetables like moringa, cabbage, and carrot. Additionally, the area is also familiar with the production and consumption of fish [27-29].

\subsection{Study Design. A facility-based cross-sectional study was} employed.

2.3. Source Population. All adults diagnosed with type 2 diabetes mellitus were on regular follow-up at Arba Minch General Hospital, diabetes follow-up clinic.

2.4. Study Population. Those selected adult patients with type 2 diabetes who had regular follow-up and fulfilled the inclusion criteria were considered as our study population. Adult patients with type 2 diabetes who had follow-up for at least six months at Arba Minch General Hospital were included in the study, whereas pregnant mothers and mentally ill patients who were unable to respond were excluded from the study.

\subsection{Sample Size Determination and Sampling Procedure.} The sample size was determined using a single population proportion formula. The assumptions considered were $p=51.4 \%$, the proportion of poor dietary practice taken from a study performed in Addis Ababa among patients with type 2 diabetes [25], 95\% confidence interval, and 5\% margin of error. Based on this assumption, the calculated sample size was 384 . Because the source population was 2,000, which is less than 10,000 , we used the population correction formula and the sample become 320 . After considering the $10 \%$ 
nonresponse rate, the sample size required for the research was 352. A systematic random sampling technique was used.

2.6. Data Collection Tools. The dietary practice was assessed by using the modified form of the nineteen-item Morisky medication adherence scale adapted from different literatures $[25,30,31]$. Questions about knowledge on diabetes were adapted from literature [32]. Questions about household food insecurity were measured using the Food and Nutrition Technical Assistance (FANTA) tool called Household Food Insecurity Access Scale (HFIAS) [33]. The respondents were asked about the occurrence of the condition that was whether the condition in the question happened at all in the past four weeks (yes or no). For respondents who answered "yes" to the occurrence question, the frequency of occurrence of the condition was asked to determine whether the condition rarely happened (once or twice), sometimes (three to ten times), or often (more than ten times) in the past four weeks. Mental- and behaviorrelated questions were developed by adapting and modifying from different literatures [34, 35]. Depression and anxiety status were assessed by using the Hospital Anxiety and Depression Scale (HADS), and the items rated on a fourpoint scale range from 0 to 3 [36-38].

2.7. Measurement. Anthropometric measurements were taken using standardized techniques and calibrated equipment. Height was measured using a stadiometer at the Frankfurt plane; participants stood in an erect posture with their shoulder level and hand at their side, thighs and heels together at a comfortable position, buttocks, scapula, and head positioned in contact with a vertical stand of stadiometer. During the measurement, respondents took off their shoes and the result was recorded to the nearest $0.1 \mathrm{~cm} \mathrm{[39].}$ Weight was measured three times by digital scale (Seca Germany), to the nearest $0.1 \mathrm{~kg}$ in light indoor clothing with bare feet. The scale was calibrated to zero before and after each measurement. Body mass index (BMI) was calculated as BMI: body weight $(\mathrm{kg}) /$ body height $\left(\mathrm{m}^{2}\right)$. Waist circumference (WC) was measured midway between the inferior angle of the 10th ribs and the iliac crest at the end of normal expiration to the nearest $1 \mathrm{~cm}$ using a nonstretchable rubber measuring tape, participants in an upright position, with arms relaxed at the side, and feet evenly spread apart [39, 40]. Nutritional status was categorized into 4 groups; underweight with $\mathrm{BMI}<18.50 \mathrm{~kg} / \mathrm{m}^{2}$, normal if BMI $18.50-24.99 \mathrm{~kg} / \mathrm{m}^{2}$, overweight if BMI $25-29.99 \mathrm{~kg} / \mathrm{m}^{2}$, and obese if $B M I \geq 30 \mathrm{~kg} / \mathrm{m}^{2}$. Central obesity was defined by waist circumference of $>102 \mathrm{~cm}$ for men and $>88 \mathrm{~cm}$ for women $[39,41]$.

2.8. Data Processing and Analytical Procedures. The data were entered into EpiData software version 3.1 and then exported to SPSS window version 21 for data cleaning and analysis. Descriptive statistics including frequency, percentages, and summary measures (mean and standard deviation) were performed. Fulfillment of chi-square assumption was checked to select variables for logistic regression. Bivariate logistic regression was performed to select candidate variables for multivariable binary logistic regression. All variables that had $p$-value $<0.25$ in bivariate analysis were entered into the multivariable logistic regression model to assess the association between dependent and independent variables. The odds ratio was used to measure the degree of association.

Principal component analysis (PCA) was performed for the household wealth index after checking the assumptions for PCA. In the final iteration step, the factor score was taken and ranked into tertials. Dietary practice status score was computed by taking the mean score of 19 questions and labeled them as good and poor dietary practice for above and below the mean value, respectively. Family support was calculated by summing the scores of 12 items and obtaining the mean of the summation, and finally the mean score was dichotomized to yes or no alternatives for the presence and absence of family support, respectively. Patients' knowledge about diabetes was similarly calculated by taking the mean values of 24 questions and labeling as good and poor knowledge for above and below the mean value, respectively.

Food security status was computed by using the HFIAS occurrence, and frequency questions and Insecurity Access Scale score were analyzed based on the HFIAS criteria and categorized into food secured, mildly food insecure, moderate food insecure, and sever food insecure [33].

Anxiety was computed by taking the sum of seven questions and labeled as yes and no for the presence and absence of anxiety with greater than or equal to 8 and less than 8 , respectively. Depression was computed by taking the sum of seven questions and labeled as yes and no for the presence and absence of depression with greater than or equal to 8 and less than 8 , respectively. Multicollinearity was checked by variance inflation factors, and the goodness-of-fit model by Hosmer-Lemeshow for $p$-value $>0.05$ was checked. A multivariable logistic regression model was used for factors associated with the dietary practice, and statistical significance was defined at a $p$-value of less than 0.05. Data quality was assured by the proper designing of the questionnaire. The questionnaire was pretested on $5 \%$ of the sample size in the nearby hospital, Chencha Hospital.

Cronbach's alpha was checked for wealth index and dietary practice with the value of 0.85 and 0.74 , respectively. Data collectors were trained for one day on how to conduct the data collection and supervision, respectively, and for experienced data collector's priority was given. After completion of the data collection, each questionnaire was checked for completeness and consistency on a daily basis. Anthropometric measurements were standardized by giving training for data collectors, and instruments were calibrated each day. Before the study began, ethical clearance was obtained from the ethical review committee of the Jimma University with a reference number of IRB 00060/2020. Official permission was secured from Arba Minch General Hospital. Participants provided written consent before the interviews. Confidentiality was ensured throughout the process of the study. The consent of each participant was taken by the data collectors and kept in their respective questionnaire and confidentially kept. 


\section{Result}

3.1. Sociodemographic and Economic Characteristics. More than half of the respondents, 197 (56.0\%), were men. More than two-thirds of the respondents (72.4\%) were, married and nearly half $(49.1 \%)$ of participants were secondary and above educational status. About one-third $(33.2 \%)$ of participants were government employees. Similarly, about one-third (33.24\%) of the participants were found in the lowest wealth category. Regarding family support, two hundred forty-one $(68.5 \%)$ respondents had no had family support (Table 1 ). Among respondents that reside in households with moderate food insecurity, more than half $(57.7 \%)$ were practicing a poor diet.

3.2. Health- and Treatment-Related Characteristics of $\mathrm{Pa}$ tients with Type 2 Diabetes. More than half of respondents (54.8\%) were diagnosed with the disease less or equal to 5 years back. About $39.2 \%$ of the respondents had comorbidity. Regarding the medication regimen, more than twothirds $(69.3 \%)$ of the respondents were on oral medication and $27(7.7 \%)$ were on both oral and insulin injection. Nearly two-thirds $(64.8 \%)$ of the respondents regularly attended diabetic education. Most of the respondents (88.6\%) received nutrition education related to diabetes. Regarding body mass index, $34.9 \%, 38.1 \%$, and $23.9 \%$ of the respondents were normal, overweight, and obese, respectively. Likewise, $71.3 \%$ had central obesity. More than half $(51.7 \%)$ of the respondents were members of the Ethiopian Diabetes Association. Most (82.1\%) of the respondents had inadequate glycemic control (Table 2).

3.3. Mental-and Behavior-Related Characteristics of Patients with Type 2 Diabetes. Regarding alcohol consumption, fortyfour $(12.5 \%)$ respondents used to drink alcohol, and eight $(2.3 \%)$ of the respondents were smokers. Similarly, $2.3 \%$ of the respondents reported that they chewed khat. According to this study, there was no diabetes-related food taboo among the respondents. Seventy-eight (22.2\%) respondents had experienced anxiety. Among the respondents, ninetyfive $(26.9 \%)$ had experienced depression (Table 3 ).

3.4. Dietary Practice and Other Related Characteristics. Among the respondents, the majority (82.4\%) did not consume food outside their home. Two hundred ninety-five $(83.8 \%)$ respondents answered that vegetables were available in their area. From the respondents, fifty (14.2\%) respondents had faced difficulty to choose foods. More than onethird $(34.1 \%)$ of the respondents had a fasting history before the diagnosis of diabetes, and seventy-two (20.5\%) respondents had fasted after the diagnosis of diabetes. More than half $(57.7 \%)$ of the respondents had poor knowledge about diabetes. This study indicated that two hundred nine $(40.6 \%, 95 \%$ CI $(35.76,46.0))$ of respondents had poor dietary practice (Table 4 ).
TABLE 1: Sociodemographic and economic characteristics of diabetic patients attending follow-up at Arba Minch General Hospital, South Ethiopia, $2020(n=352)$.

\begin{tabular}{|c|c|c|c|}
\hline Variables & Categories & $\begin{array}{l}\text { Frequency } \\
(n=352)\end{array}$ & Percent \\
\hline \multirow{3}{*}{ Age } & $<40$ & 75 & 21.3 \\
\hline & $40-60$ & 211 & 59.9 \\
\hline & $>60$ & 66 & 18.8 \\
\hline \multirow{2}{*}{ Sex } & Male & 197 & 56.0 \\
\hline & Female & 155 & 44.0 \\
\hline \multirow{2}{*}{ Residence } & Urban & 287 & 81.5 \\
\hline & Rural & 65 & 18.5 \\
\hline \multirow{4}{*}{ Marital status } & Single & 26 & 7.4 \\
\hline & Married & 255 & 72.4 \\
\hline & Widowed & 33 & 9.4 \\
\hline & Divorced & 38 & 10.8 \\
\hline \multirow{3}{*}{$\begin{array}{l}\text { Educational } \\
\text { status }\end{array}$} & $\begin{array}{l}\text { No formal } \\
\text { education }\end{array}$ & 106 & 30.1 \\
\hline & Primary education & 73 & 20.7 \\
\hline & $\begin{array}{c}\text { Secondary and } \\
\text { above }\end{array}$ & 173 & 49.1 \\
\hline \multirow{3}{*}{ Occupation } & Unemployed & 133 & 37.8 \\
\hline & $\begin{array}{l}\text { Government } \\
\text { employed }\end{array}$ & 117 & 33.2 \\
\hline & Private employed & 102 & 29.0 \\
\hline \multirow{3}{*}{$\begin{array}{l}\text { Household } \\
\text { wealth }\end{array}$} & Low & 117 & 33.24 \\
\hline & Middle & 118 & 33.52 \\
\hline & High & 117 & 33.24 \\
\hline \multirow{2}{*}{ Family support } & Yes & 111 & 31.5 \\
\hline & No & 241 & 68.5 \\
\hline \multirow{3}{*}{ Food security } & Secure & 128 & 36.4 \\
\hline & Mild & 120 & 34.1 \\
\hline & Moderate & 104 & 29.5 \\
\hline
\end{tabular}

3.5. Factors Associated with Dietary Practice of Patients with Type 2 Diabetes. Bivariate and multivariable logistic regression analysis was performed to identify factors associated with the dietary practice of patients with type 2 diabetes. On the bivariate analysis, educational status, residence, household food security status, duration of diabetes, diabetic knowledge, despondency, depression, and nutrition education showed a $p$-value of $<0.25$ and became a candidate for multivariable analysis. On multivariable analysis, by taking other variables as constant, patients who had not attended formal education and those at primary education level were 3.0 and 2.2 times more likely to have poor dietary practice as compared to secondary education and above ( $\mathrm{AOR}=3.0$; 95\%CI (1.6-5.5) $)$ and $(\mathrm{AOR}=2.2 ; 95 \% \mathrm{CI} \quad(1.1-4.4))$, respectively.

Participants from the moderately food-insecure households were 5.3 times more likely to have poor dietary practice as compared to food-secure households ( $\mathrm{AOR}=5.3$; 95\%CI (2.8-9.9)). Those patients having depression were 5.9 times more likely to have poor dietary practice than the counter ones $(\mathrm{AOR}=5.9 ; 95 \% \mathrm{CI}(3.0-11.4))$. Patients who did not get nutrition education were 2.2 times more likely to have poor dietary practice compared to those who get nutrition education $(\mathrm{AOR}=2.2$; 95\%CI (1.1-4.6)) (Table 5). 
TABLE 2: Health- and treatment-related characteristics of diabetic patients attending follow-up at Arba Minch General Hospital, South Ethiopia, $2020(n=352)$.

\begin{tabular}{|c|c|c|c|}
\hline Variables & Categories & Frequency $(n=352)$ & Percent \\
\hline \multirow{2}{*}{ Duration of diabetes } & $\leq 5$ year & 193 & 54.8 \\
\hline & $>5$ year & 159 & 45.2 \\
\hline \multirow{2}{*}{ Comorbidity } & Yes & 138 & 39.2 \\
\hline & No & 214 & 60.8 \\
\hline \multirow{4}{*}{ Current medication } & Insulin injection & 74 & 21.0 \\
\hline & Oral medication & 244 & 69.3 \\
\hline & Both & 27 & 7.7 \\
\hline & Diet alone & 7 & 2.0 \\
\hline \multirow{2}{*}{ Regularly attended a diabetic education } & Yes & 228 & 64.8 \\
\hline & No & 124 & 35.2 \\
\hline \multirow{2}{*}{ Got nutrition education } & Yes & 312 & 88.6 \\
\hline & No & 40 & 11.4 \\
\hline \multirow{2}{*}{ Despondency } & Yes & 184 & 52.3 \\
\hline & No & 168 & 47.7 \\
\hline \multirow{2}{*}{ Member of Ethiopian diabetic association } & Yes & 182 & 51.7 \\
\hline & No & 170 & 48.3 \\
\hline \multirow{4}{*}{ Body mass index } & Underweight & 11 & 3.1 \\
\hline & Normal & 123 & 34.9 \\
\hline & Overweight & 134 & 38.1 \\
\hline & Obese & 84 & 23.9 \\
\hline \multirow{2}{*}{ Central obesity } & Normal & 101 & 28.7 \\
\hline & Obese & 251 & 71.3 \\
\hline \multirow{2}{*}{ Members of Ethiopian diabetic association } & Yes & 182 & 51.7 \\
\hline & No & 170 & 48.3 \\
\hline \multirow{2}{*}{ Glycemic control } & Adequate glycemic control & 63 & 17.9 \\
\hline & Inadequate glycemic control & 289 & 82.1 \\
\hline
\end{tabular}

TABLE 3: Substance using status of diabetic patients attending follow-up at Arba Minch General Hospital, South Ethiopia, 2020 ( $n=352$ ).

\begin{tabular}{|c|c|c|c|}
\hline Variables & Categories & Frequency $(n=352)$ & Percent \\
\hline \multirow{2}{*}{ Ever drunk alcohol } & Yes & 44 & 12.5 \\
\hline & No & 308 & 87.5 \\
\hline \multirow{2}{*}{ Currently alcohol drinking $(n=44)$} & Yes & 32 & 72.7 \\
\hline & No & 12 & 27.3 \\
\hline \multirow{2}{*}{ Ever smoked cigarette } & Yes & 8 & 2.3 \\
\hline & No & 344 & 97.7 \\
\hline \multirow{2}{*}{ Currently smoking cigarette $(n=8)$} & Yes & 3 & 37.5 \\
\hline & No & 5 & 62.5 \\
\hline \multirow{2}{*}{ Ever chewed khat } & Yes & 8 & 2.3 \\
\hline & No & 344 & 97.7 \\
\hline \multirow{2}{*}{ Currently chewing khat $(n=8)$} & Yes & 4 & 50.0 \\
\hline & No & 4 & 50.0 \\
\hline \multirow{2}{*}{ Depression } & No depression & 257 & 73.1 \\
\hline & Have depression & 95 & 26.9 \\
\hline \multirow{2}{*}{ Anxiety } & No anxiety & 274 & 77.8 \\
\hline & Anxiety & 78 & 22.2 \\
\hline
\end{tabular}

But residence, duration of knowledge about diabetes, and patient's despondency were not statistically associated with poor dietary practice (Table 5 ).

Hosmer-Lemeshow's goodness-of-fit test produces the chi-square of 2.962 with $p$ value of 0.94 and 8 degrees of freedom; hence, the model was good for the data.

\section{Discussion}

The findings of the present study revealed that a significant proportion $(40.6 \%)$ of diabetic patients had poor dietary practice. The finding is higher than previous reports from Kenya, Nigeria, and Yemen, which were 26.1\%, 24.0\%, and 
TABle 4: Dietary-related characteristics of diabetic patients attending follow-up at Arba Minch General Hospital, South Ethiopia, 2020 $(n=352)$.

\begin{tabular}{|c|c|c|c|}
\hline Variables & Categories & Frequency $(n=352)$ & Percent \\
\hline \multirow{2}{*}{ Eating out of home } & Yes & 62 & 17.6 \\
\hline & No & 290 & 82.4 \\
\hline \multirow{2}{*}{ Availability of vegetables } & Yes & 295 & 83.8 \\
\hline & No & 57 & 16.2 \\
\hline \multirow{2}{*}{ Availability of fruits } & Yes & 291 & 82.7 \\
\hline & No & 61 & 17.3 \\
\hline \multirow{2}{*}{ Faced difficulty in choosing food? } & Yes & 50 & 14.2 \\
\hline & No & 302 & 85.8 \\
\hline \multirow{2}{*}{ Worry about high cost of foods } & Yes & 188 & 53.4 \\
\hline & No & 164 & 46.6 \\
\hline \multirow{2}{*}{ History of fasting before diabetes } & Yes & 120 & 34.1 \\
\hline & No & 232 & 65.9 \\
\hline \multirow{2}{*}{ History of fasting after diabetes } & Yes & 72 & 20.5 \\
\hline & No & 280 & 79.5 \\
\hline \multirow{2}{*}{ Diabetic knowledge } & Good & 203 & 57.7 \\
\hline & Poor & 149 & 42.3 \\
\hline \multirow{2}{*}{ Dietary practice } & Poor & 143 & 40.6 \\
\hline & Good & 209 & 59.4 \\
\hline
\end{tabular}

TABLE 5: Multivariable logistic regression model showing factors associated with the dietary practice of patients with type 2 diabetes in Arba Minch General Hospital, Southern Ethiopia, $2020(n=352)$.

\begin{tabular}{|c|c|c|c|c|c|c|}
\hline \multirow{2}{*}{ Variables } & \multirow{2}{*}{ Category } & \multicolumn{2}{|c|}{ Dietary practice } & \multirow{2}{*}{ COR (95\%C.I) } & \multirow{2}{*}{ AOR (95\%C.I) } & \multirow{2}{*}{$p$ value } \\
\hline & & Poor $(\%)$ & Good (\%) & & & \\
\hline \multirow{3}{*}{ Educational status } & No formal education & $51(48.1)$ & $55(51.9)$ & $1.7(1.1-2.7)$ & $3.0(1.6-5.5)$ & 0.001 \\
\hline & Primary education & $30(41.1)$ & $43(58.9)$ & $1.2(0.7-2.2)$ & $2.2(1.1-4.4)$ & 0.030 \\
\hline & Secondary and above & $62(35.8)$ & $111(64.2)$ & 1 & 1 & \\
\hline \multirow{2}{*}{ Residence } & Urban & $112(39.0)$ & $175(61.0)$ & 1 & 1 & \\
\hline & Rural & $31(47.7)$ & $34(52.3)$ & $1.4(0.8-2.4)$ & $1.6(0.8-2.9)$ & 0.171 \\
\hline \multirow{3}{*}{ Food security status } & Secure & $37(28.9)$ & $91(71.1)$ & 1 & 1 & \\
\hline & Mildly insecure & $46(38.3)$ & $74(61.7)$ & $1.5(0.9-2.6)$ & $1.4(0.8-2.6)$ & 0.246 \\
\hline & Moderately insecure & $60(57.7)$ & $44(42.3)$ & $3.4(1.9-5.8)$ & $5.3(2.8-9.9)$ & $<0.001$ \\
\hline \multirow{2}{*}{ Duration of diabetes in years } & $\leq 5$ year & $87(45.1)$ & $106(54.9)$ & 1 & 1 & \\
\hline & $>5$ year & $56(35.2)$ & $103(64.8)$ & $0.7(0.4-0.9)$ & $0.7(0.4-1.1)$ & 0.110 \\
\hline \multirow{2}{*}{ Diabetes knowledge } & Good knowledge & $76(37.4)$ & $127(62.6)$ & 1 & 1 & \\
\hline & Poor knowledge & $67(45.0)$ & $82(55.0)$ & $1.4(0.9-2.1)$ & $1.7(0.9-2.9)$ & 0.061 \\
\hline \multirow{2}{*}{ Despondency } & Yes & $66(35.9)$ & $118(64.1)$ & $0.6(0.4-1.1)$ & $0.6(0.4-1.1)$ & 0.056 \\
\hline & No & $77(45.8)$ & $91(54.2)$ & 1 & 1 & \\
\hline \multirow{2}{*}{ Depression } & No depression & $91(35.4)$ & $166(64.6)$ & 1 & 1 & \\
\hline & Have depression & $52(54.4)$ & $43(45.3)$ & $2.2(1.4-3.6)$ & $5.9(3.0-11.4)$ & $<0.001$ \\
\hline \multirow{2}{*}{ Nutrition education } & Yes & $121(38.8)$ & $191(61.2)$ & 1 & 1 & \\
\hline & No & $22(55.0)$ & $18(45.0)$ & $2(1.1-3.9)$ & $2.2(1.1-4.6)$ & 0.038 \\
\hline
\end{tabular}

$32.4 \%$, respectively [42-44]. The disparity might be attributed to the sociodemographic and economic domains of the study participants. This might be because of the different assessment methods used to assess the level of dietary practice in those studies. Additionally, in the current study substantial proportion of patients $(42.3 \%)$ had poor knowledge regarding diabetes which might have made them to consume monotonous and undiversified diets. In the present study, almost one-fifth of patients had eaten out of home, which might hinder the patients' dietary practice to step back. Concurrently, in this study huge proportion of individuals had no family support which may play a great role in poor dietary habits.
The finding of this study was in line with studies performed in Botswana, Pakistan, and Jimma, which showed that the prevalence of poor dietary practice was $37.0 \%, 36.1 \%$, and $36 \%$, respectively $[42,45,46]$. But in some other studies from Ethiopia and elsewhere, the proportion of poor dietary practice was much higher than this study [25, 30, 47-49]. The difference might be accounted for by differences in study period and measurement. Furthermore, the sedentary and motorized way of life in those areas might increase exposure to the consumption of fast and energy-dense foods, which might subsequently make the patients' dietary practice to be more deprived [50]. 
This study also showed that patients' educational status had a significant association with dietary practice. Patients who had not attended formal education and being at primary education were more likely to have poor dietary practice as compared with college graduates and above, respectively. The finding was consistent with a study conducted in Kenya and Bahir Dar [30, 51]. This might be because the patients' educational status had a direct relation with their dietary practice. Patients with higher educational status would likely give due attention to a healthy and quality diet because education gives an opportunity for patients to have better health literacy, which may in turn improve dietary practice. Moreover, those with lower education might have a limited chance of getting dietary information [52].

According to this study, the poor dietary practice was higher among patients residing in food-insecure households. Similarly, a study performed in the United States of America (USA) showed that food insecurity had a negative effect on patients' dietary habits [53]. It is apparent that patients from food-insecure households would likely have economic constraints that might adversely affect the household's access to diversified food. Likewise, evidence indicated that less expensive and calorie-dense food consumption among foodinsecure households might also play a crucial role $[54,55]$. Additionally, patients might be engaged in negative coping strategies to tackle the food insecurity situation, which in turn might play a key role in their poor dietary practice $[56,57]$. Furthermore, $14.2 \%$ of the patients in this study faced difficulty to choose foods. This might be because of a limited resource since one-third of the patients in this study were in a wealth index of the lower category.

The findings of this study indicated that patients who had depression were more likely to have poor dietary practices than those having no depression. Similarly, a finding from Ghana, Saudi Arabia, and the Republic of Korea showed that depression status was higher among patients with poor dietary habits [58-60]. Depression might pose an adverse effect on a patient's decision-making ability to their general health and toward wise food choices and self-care [61, 62]. Additionally, the association might be because of less preference for social interaction of depressed patients, and they might not disclose their medical history and seek social support from their family. In this study, more than twothirds $(68.5 \%)$ of patients had no family support. Also, more than one-third of patients had comorbidities other than diabetes that could create another burden for the patients and might have played a role in affecting healthy dietary habit in the study area.

In this study, the poor dietary practice was higher among diabetic patients who had not received nutrition education. The finding is consistent with a study conducted in Bahir Dar, Northwest Ethiopia [25], but was not in agreement with a study performed in the capital, Addis Ababa. It is evident that the dissemination of appropriate information is vital and the first step to make healthy choices. A study performed in Kenya reported that good dietary practice and higher dietary diversity among patients were associated with better nutrition knowledge [51]. The result of this study implied that diabetic patients' dietary practice was undesirably colossal. As a result, there is a need to strengthening of healthy diet-centered diabetic care and focusing on the identified factors for the poor dietary practice in the study area.

This study considered new variables like depression and food insecurity in relation to dietary practice that were, to the best of our knowledge, not assessed in other previous studies performed so far. Using a small sample size for the study and employing a cross-sectional study design were limitations of this study. Additionally, recall bias might have been there in the tool used to obtain data about household food insecurity and social desirability bias might be introduced for questions assessing diabetic knowledge. As a result, interpretation of the findings of this study needs caution.

\section{Conclusions}

The proportion of poor dietary practice among patients with type 2 diabetes on follow-up attending at Arba Minch General Hospital was high. Patients' educational status, household food security status, depression status, and receipt of nutrition education were statistically significantly associated with their poor dietary practice. Health information dissemination concerning healthy dietary practices should be strengthened and delivered in the form of a package. Health professionals should have a common understanding and follow patients' adherence to the dietary recommendation and should also deliver patient-oriented nutritional education in every follow-up visit.

\section{Data Availability}

The datasets used and analyzed during the current study are included in the article.

\section{Consent}

Not applicable.

\section{Conflicts of Interest}

The authors declare that they have no conflicts of interest to disclose.

\section{Acknowledgments}

The authors would like to express their sincere thanks to the Jimma University, Institute of Health, Department of $\mathrm{Nu}$ trition and Dietetics, for providing ethical clearance. Last but not least, the authors would like to appreciate their study participants and data collectors.

\section{References}

[1] American Diabetes Association, "Diagnosis and classification of diabetes mellitus," Diabetes Care, vol. 33, pp. 62-69, 2010.

[2] A. Carroll, E. Erin, and A. Nancy, Nutrition and Diet Therapy, F.A. Davis Company, Philadelphia, PA, USA, 2015.

[3] World Health Organization, Definition, Diagnosis and Classification of Diabetes Mellitus and its Complications Report of a 
WHO Consultation Part 1, Department of Noncommunicable Disease Surveillance Geneva, Geneva, Switzerland, 1999, https://who.int/iris/handle/10665/66040.

[4] N. D. Ford, S. A. Patel, and K. M. V. Narayan, "Obesity in lowand middle-income countries: burden, drivers, and emerging challenges," Annual Review of Public Health, vol. 38, no. 1, pp. 145-164, 2017.

[5] A. Poobalan and L. Aucott, "Obesity among young adults in developing countries: a systematic overview," Current Obesity Reports, vol. 5, no. 1, pp. 2-13, 2016.

[6] M. S. Nnyepi, N. Gwisai, M. Lekgoa, and T. Seru, "Evidence of nutrition transition in southern Africa," Proceedings of the Nutrition Society, vol. 74, no. 4, pp. 478-486, 2015.

[7] P. Saeedi, I. Petersohn, P. Salpea et al., "Global and regional diabetes prevalence estimates for 2019 and projections for 2030 and 2045: results from the international diabetes federation diabetes atlas," Diabetes Research and Clinical Practice, vol. 157, Article ID 107843, 2019.

[8] American Diabetes Association, "Standards of medical care in diabetes 2019 abridged for primary care providers," Diabetes Care, vol. 37, 2019.

[9] C. Annalijn, M. Pablo, K. Kay-Tee, W. Nicholas, and F. Nita, "Dietary diversity, diet cost, and incidence of type 2 diabetes in the United Kingdom: a prospective cohort study," PLoS Medicine's, vol. 13, no. 7, Article ID e1002085, 2016.

[10] D. Jakubowicz, Z. Landau, S. Tsameret et al., "Reduction in glycated hemoglobin and daily insulin dose alongside circadian clock upregulation in patients with type 2 diabetes consuming a three-meal diet: a randomized clinical trial," Diabetes Care, vol. 42, no. 12, pp. 2171-2180, 2019.

[11] L. Garcia-Molina, A. M. Lewis-Mikhael, B. Riquelme-Gallego, N. Cano-Ibanez, M. J. Oliveras-Lopez, and A. Bueno-Cavanillas, "Improving type 2 diabetes mellitus glycaemic control through lifestyle modification implementing diet intervention: a systematic review and meta-analysis," European Journal of Nutrition, vol. 59, 2019.

[12] F. Marion and E. Alison, American Diabetes Association; Guide to Nutrition Therapy for Diabetes, American Diabetes Association, Arlington County, Virginia, USA, 2012.

[13] S. O. Oti, S. Van de Vijver, and C. Kyobutungi, "Trends in non-communicable disease mortality among adult residents in Nairobi's slums, 2003-2011," Global Health Action, vol. 7, no. 1, Article ID 25533, 2014.

[14] P. Kim Streatfield, W. A. Khan, A. Bhuiya et al., "Adult noncommunicable disease mortality in Africa and asia: evidence from INDEPTH health and demographic surveillance system sites," Global Health Action, vol. 7, no. 1, Article ID 25365, 2014.

[15] World Health Organization, "Noncommunicable diseases country profiles 2018," 2021, https://www.who.int/nmh/ publications/ncd-profiles-2018/en/.

[16] N. Minicuci, R. B. Biritwum, G. Mensah et al., "Sociodemographic and socioeconomic patterns of chronic noncommunicable disease among the older adult population in Ghana," Global Health Action, vol. 7, no. 1, Article ID 21292, 2014.

[17] World Health Organization, Global Report on Diabetes, World Health Organization, Geneva, Switzerland, 2016.

[18] World Health Organization, World Health Statistics Overview 2019: Monitoring Health for the SDGs, Sustainable Development Goals, World Health Organization, Geneva, Switzerland, 2019.

[19] P. Riobo Servan, "Diet recomendations in diabetes and obesity,” Nutricion Hospitalaria, vol. 35, pp. 109-115, 2018.
[20] A. Mohandas, S. K. Bhasin, M. Upadhyay, and S. V. Madhu, "Diabetes self care activities among adults 20 years and above residing in a resettlement colony in East Delhi," Indian Journal of Public Health, vol. 62, pp. 104-110, 2018.

[21] K. Audain, L. Levy, and B. Ellahi, "Sugar-sweetened beverage consumption in the early years and implications for type- 2 diabetes: a sub-Saharan Africa context," Proceedings of the Nutrition Society, vol. 78, no. 4, pp. 547-553, 2019.

[22] Ethiopian Ministry of Health, Federal Democratic Republic of Ethiopia; National Nutrition Program, Ethiopian Ministry of Health, Ethiopia, 2016.

[23] V. Stephani, D. Opoku, and D. Beran, "Self-management of diabetes in Sub-Saharan Africa: a systematic review," BMC Public Health, vol. 18, no. 1, p. 1148, 2018.

[24] M. Akibu and N. Tadesse, "Adherence to dietary recommendation and associated factors among diabetic patients in Ethiopian teaching hospitals," The Pan African Medical Journal, vol. 33, p. 260, 2019.

[25] A. Worku, S. Mekonnen, and M. Mesele, Dietary Practice and Associated Factors Among Type 2 Diabetic Patients: A Cross Sectional Hospital Based study, Addis Ababa, Ethiopia, Springer, Berlin, Germany, 2015.

[26] Gamo Zone Health Department, Annual Zonal Health Report, Gamo Zone Health Department, Gamo Gofa, Ethiopia, 2019.

[27] L. A. Hirpo, "Fisheries production system scenario in Ethiopia," International Journal of Fisheries and Aquatic Studies, vol. 5, pp. 79-84, 2017.

[28] A. Behailu and J. Kebede, "A study on the causes of apple (malus domestica) fruit loss at Chencha woreda of Gamo gofa zone, southern Ethiopia," Journal of Stored Products and Postharvest Research, vol. 9, pp. 72-77, 2018.

[29] Z. Ambisa, B. Tesfa, T. Olani, and D. Abdeta, "Review on the production and marketing of banana in Ethiopia," World Journal of Agriculture and Soil Science, vol. 2, 2019.

[30] Y. M. Demilew, A. T. Alem, and A. A. Emiru, "Dietary practice and associated factors among type 2 diabetic patients in felege hiwot regional referral hospital, Bahir dar, Ethiopia," BMC Research Notes, vol. 11, no. 1, p. 434, 2018.

[31] S. Plakas, D. Mastrogiannis, M. Mantzorou et al., "Validation of the 8-item Morisky medication adherence scale in chronically ill ambulatory patients in rural Greece," Open Journal of Nursing, vol. 06, no. 03, pp. 158-169, 2016.

[32] J. T. Fitzgerald, M. M. Funnell, R. M. Anderson, R. Nwankwo, R. B. Stansfield, and G. A Piatt, "Validation of the revised brief diabetes knowledge test (DKT2)," The Diabetes Educator, vol. 42, pp. 178-87, 2016.

[33] J. Coates, A. Swindale, and P. Bilinsky, Household Food Insecurity Access Scale (HFIAS) for Measurement of Food Access: Indicator Guide VERSION 3. Food and Nutrition Technical Assistance III Project (FANTA), USAID, Washington, D.C., USA, 2007.

[34] H. Wang, Z. Song, Y. Ba, L. Zhu, and Y. Wen, "Nutritional and eating education improves knowledge and practice of patients with type 2 diabetes concerning dietary intake and blood glucose control in an outlying city of China," Public Health Nutrition, vol. 17, no. 10, pp. 2351-2358, 2014.

[35] W. Getnet, W. Aycheh, and T. Tessema, "Determinants of food taboos in the pregnant women of the awabel district, east gojjam zone, amhara regional state in Ethiopia," Hindawi, Advances in Public Health, vol. 6, 2018.

[36] A. Aklilu, "Reliability and validity of the Ethiopian version of the hospital anxiety and depression scale (HADS) in HIV 
infected patients," PLoS One, vol. 6, no. 1, Article ID e16049, 2011.

[37] T. Tiki, "Prevalence and associated factors of depression among type 2 diabetes mellitus patients on follow up at ambo general hospital, oromia regional state, Ethiopia, institutional based cross sectional study," Journal of Depression \& Anxiety, vol. 6, 2017.

[38] B. Duko, A. Gebeyehu, and G. Ayano, "Prevalence and correlates of depression and anxiety among patients with tuberculosis at WolaitaSodo university hospital and sodo health center, WolaitaSodo, south Ethiopia, cross sectional study," BMC Psychiatry, vol. 15, pp. 214-217, 2015.

[39] V. R. Preedy, Handbook of Anthropometry Physical Measures of Human Form in Health and Disease, Springer, Berlin, Germany, 2012.

[40] International Society for the Advancement of Kinanthropometry, International Standards for Anthropometric Assessment, International Society for the Advancement of Kinanthropometry, Australia, 2001.

[41] C. T. McEvoy, C. R. Cardwell, J. V. Woodside, I. S. Young, S. J. Hunter, and M. C. McKinley, "A posteriori dietary patterns are related to risk of type 2 diabetes: findings from a systematic review and meta-analysis," Journal of the Academy of Nutrition and Dietetics, vol. 114, no. 11, pp. 1759-1775, Article ID e1754, 2014.

[42] A. Alhariri, F. Daud, A. Almaiman, and S. Ayesh, "Factors associated with adherence to diet and exercise among type 2 diabetes patients in Hodeidah city,Yemen," Diabetes Management, vol. 7, pp. 264-271, 2017.

[43] A. Isara, L. Omonigho, and D. Olaoye, "Non-medical management practices for type 2 diabetes in a teaching hospital in southern Nigeria," African Journal of Diabetes Medicine, vol. 22, 2014.

[44] C. Musee and O. W. Omondi, "Dietary adherence pattern in the context of type 2 diabetic management within clinical setting, Kenya," International Journal of Diabetes Research, vol. 5, pp. 26-34, 2016.

[45] M. U. Farooq, F. Mushtaq, Z. Naeem, S. Iqbal, S. Naseem, and O. Ishtiaq, "Dietary habits and practices of type-2 diabetic patients in a tertiary care centre of Islamabad, Pakistan," JPMA. The Journal of the Pakistan Medical Association, vol. 68, pp. 825-830, 2018.

[46] G. Zeleke and D. Charles, "Prevalence and predictors of nonadherence to diet and physical activity recommendations among type 2 diabetes patients in southwest Ethiopia: a crosssectional study," Hindawi: International Journal of Endocrinology, vol. 2020, Article ID 1512376, 2020.

[47] S. Kasturia, M. Ali, K. Narayan et al., "Diets for South Asians with diabetes: recommendations, adherence, and outcomes," Asia Pacific Journal of Clinical Nutrition, vol. 27, pp. 823-831, 2018.

[48] A. Klinovszky, I. M. Kiss, O. Papp-Zipernovszky, C. Lengyel, and N. Buzás, "Associations of different adherences in patients with type 2 diabetes mellitus," Patient Preference and Adherence, vol. 13, pp. 395-407, 2019.

[49] J. Parajuli, F. Saleh, N. Thapa, and L. Ali, "Factors associated with nonadherence to diet and physical activity among Nepalese type 2 diabetes patients; a cross sectional study," BMC Research Notes, vol. 7, no. 1, p. 758, 2014.

[50] S. Biadgilign, T. Mgutshini, D. Haile, B. Gebremichael, Y. Moges, and K. Tilahun, "Epidemiology of obesity and overweight in sub-Saharan Africa: a protocol for a systematic review and meta-analysis," BMJ Open, vol. 7, no. 11, Article ID e017666, 2017.
[51] E. M. Wahome, W. K. Makau, and W. K. Kiboi, "Predictors of dietary practices and nutritional status among diabetic type II patients in Kiambu County, Kenya," International Journal of Community Medicine and Public Health, vol. 5, no. 7, pp. 2726-2734, 2018.

[52] J. Lê, J. Dallongeville, A. Wagner et al., "Attitudes toward healthy eating: a mediator of the educational level-diet relationship," European Journal of Clinical Nutrition, vol. 67, no. 8, pp. 808-814, 2013.

[53] W. J. Heerman, K. A. Wallston, C. Y. Osborn et al., "Educational and psychological aspects Food insecurity is associated with diabetes self-care behaviours and glycaemic control," Diabetic Medicine, vol. 33, no. 6, pp. 844-850, 2016.

[54] A. Drewnowski and S. Specter, "Poverty and obesity: the role of energy density and energy costs," The American Journal of Clinical Nutrition, vol. 79, no. 1, pp. 6-16, 2004.

[55] K. Lunze, E. Yurasova, B. Idrisov, N. Gnatienko, and L. Migliorini, "Food security and nutrition in the Russian Federation a health policy analysis," Global Health Action, vol. 8, Article ID 27537, 2015.

[56] M. E. Morales and S. A. Berkowitz, "The relationship between food insecurity, dietary patterns, and obesity," Current $\mathrm{Nu}$ trition Reports, vol. 5, no. 1, pp. 54-60, 2016.

[57] T. A. Sisha, "Household level food insecurity assessment: evidence from panel data, Ethiopia," Scientific African, vol. 7, Article ID e00262, 2020.

[58] H. Park, Y. Hong, H. Lee, E. Ha, and Y. Sung, "Individuals with type 2 diabetes and depressive symptoms exhibited lower adherence with self-care," Journal of Clinical Epidemiology, vol. 57, no. 9, pp. 978-984, 2004.

[59] I. A. Kretchy, A. Koduah, T. Ohene-Agyei, V. Boima, and B. Appiah, "The association between diabetes-related distress and medication adherence in adult patients with type 2 diabetes mellitus: a cross-sectional study," Journal of Diabetes Research, vol. 2020, Article ID 4760624, 2020.

[60] N. M. Alhunayni, A. E. Mohamed, and S. M. Hammad, "Prevalence of depression among type-II diabetic patients attending the diabetic clinic at arar national guard primary health care center, Saudi Arabia," Psychiatry journal, vol. 2020, Article ID 9174818, 2020.

[61] E. H. B. Lin, W. Katon, M. Von Korff et al., "Relationship of depression and diabetes self-care, medication adherence, and preventive care," Diabetes Care, vol. 27, no. 9, pp. 2154-2160, 2004.

[62] J. D. McKellar, K. Humphreys, and J. D. Piette, "Depression increases diabetes symptoms by complicating patients' selfcare adherence," The Diabetes Educator, vol. 30, no. 3, pp. 485-492, 2004. 